\title{
Theoretical Advances in Aromatic Nitration
}

\author{
Francisco Sánchez-Viesca*, Reina Gómez, Martha Berros \\ Organic Chemistry Department, Faculty of Chemistry, National Autonomous University of Mexico, México, DF, México
}

\section{Email address:}

franviesca@yahoo.com (F. Sánchez-Viesca), reinagomezg@yahoo.com.mx (R. Gómez), mibe50@yahoo.com (M. Berros)

\section{To cite this article:}

Francisco Sánchez-Viesca, Reina Gómez, Martha Berros. Theoretical Advances in Aromatic Nitration. Modern Chemistry. Vol. 3, No. 1, 2015, pp. 9-13. doi: 10.11648/j.mc.20150301.12

\begin{abstract}
In this paper we want to present together our theoretical findings on aromatic nitration, involving both homocyclic and heterocyclic compounds. Our theoretical proposals have been introduced in recent years via several research communications. These theories convey new concepts in Organic Chemistry, such as Electric Hindrance, Autogenic Electromeric Effect, the formation of Precursor Complexes, as well as, short- and long-distance electric interactions in the reactive intermediates. These concepts explain the regiochemistry and the reaction yields, clearing up some obscurities found in Organic Chemistry. Thus, these theoretical considerations are filling gaps in the theory of supposedly well known chemical reactions, improving and updating the Chemical Education.
\end{abstract}

Keywords: Electric Hindrance, Noncovalent Interactions, Precursor Complexes, Reaction Mechanisms, Reactive Intermediates

\section{Introduction}

Some fundamental chemical reactions have been thoroughly studied in order to improve and update the theory related with them. We have focused our attention on the regiochemistry and the reaction yields of several nitration processes.

These advances have been communicated gradually and in isolated form, as it will be seen. Now we want to present them collectively, in a unified summary.

\section{Theoretical Part}

\subsection{Precursor Complexes and Electric Hindrance}

Acetanilide can be nitrated with sulfonitric mixture $\left(\mathrm{HNO}_{3} / \mathrm{H}_{2} \mathrm{SO}_{4}\right)$ or with acetyl nitrate $\left(\mathrm{CH}_{3} \mathrm{CO}_{2} \mathrm{NO}_{2}\right)$. In the first case p-nitroacetanilide is obtained in $90 \%$ yield and only $10 \%$ of the ortho isomer is formed [1]. With acetyl nitrate the reaction yields are inverted and the ortho isomer is obtained in $95 \%$ yield [2].

We have explained these results [3] as follows: in the nitration with acids we neglect steric hindrance as the determining factor since with acetyl nitrate a $95 \%$ yield of the ortho isomer is formed. In this second case the dipolar structure of acetyl nitrate can interact with the dipolar resonance structure of acetanilide, "Scheme 1". Thus, a reagent-substrate precursor complex can be formed, i.e., a five member chelate.

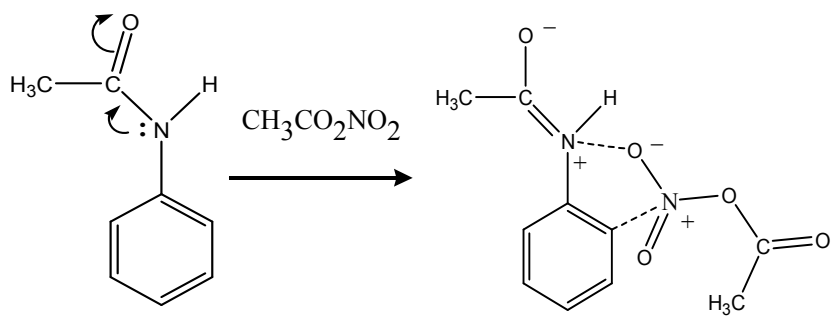

Scheme 1. Acetanilide-acetyl nitrate complex previous to nitration

Being stabilized the upper part of the chelate, the positive nitrogen atom in the acetyl nitrate reacts with the benzene ring at C-2, "Scheme 2".

In our proposal acetyl nitrate reacts without any previous dissociation. This is in complete agreement with logic and with experimental results. If this reagent produced nitronium ions, reacting as ionic nitronium acetate, the reaction products would be the same as those obtained with sulfonitric mixture, a source of nitronium ions. Besides, ${ }^{14} \mathrm{~N}-\mathrm{NMR}$ studies indicate that acetyl nitrate does not dissociate [4].

The preponderance of 4-nitroacetanilide when mixed-acid is used can be explained as follows. Due to the amide resonance in acetanilide, this compound is not expected to contribute electrons to the benzene ring, but until a positive 
ion, such as a nitronium ion, forms a $\pi$-complex and then induces polarization, i.e., until the electromeric effect $[5,6]$ occurs.

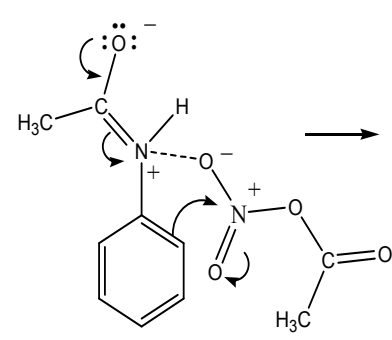<smiles>CC(=O)N[C@H]1C=CC=C[C@H]1[N+](=O)[O-]</smiles><smiles>CC(=O)Nc1ccccc1[N+](=O)[O-]</smiles><smiles>CC(=O)O</smiles>

Scheme 2. Mechanism of 2-nitroacetanilide formation

The great reactivity at position 4 can be explained by reaction at the farthest double bond from the positive nitrogen atom in acetanilide resonance structure, in order to avoid electric repulsion, "Scheme 3". We call this behaviour Electric Hindrance, since there is no reactivity at C-2.<smiles>CC1(O)CC[N+](Cc2cccc([N+](=O)[O-])c2)([N+](=O)[O-])CC1</smiles><smiles>CC(=O)[NH+]1C=CC(C)CC1</smiles><smiles>CC(=O)Nc1ccc([N+](=O)[O-])cc1</smiles>

Scheme 3. Mechanism of 4-nitroacetanilide formation

This way, we have provided the required theories to fully explain both pathways in acetanilide nitration.

This new concept, electric hindrance, has had application in order to explain other reactions, such as 2-aminopyridine nitration [7] and the quinoline and isoquinoline nitrations [8].

In the nitration of 2-aminopyridine two isomeric nitro compounds are obtained: 2-amino-3-nitropyridine and 2-amino-5-nitropyridine [9, 10]. The interesting fact is that they are obtained in very different proportions: the 5-nitro-isomer is obtained in 90\% yield and the 3-nitro-isomer in $10 \%$ yield. This great difference must be explained. Steric hindrance can be invoked, but we have found that major factors are present in these reactions.

In acidic medium, 2-aminopyridine can be protonated in the endo- and in the exo-cyclic nitrogen. However, this compound is much more reactive than pyridine. This reactivity indicates that there are protonation and deprotonation processes, the free amino group being capable of electron donor properties. Kekule structures 1 and 2 are not equivalent in order to explain this reactivity, "Fig. 1". The first, in acidic medium, forms an iminium-enamine grouping, 3, which turns to structure 4, precluding electronic contribution to the ring from the amino group. Neither the electronic-ring structure 5 is adequate, since there is no equal reactivity at the $\mathrm{C}$ atoms. There is heteronomy, not isonomy.<smiles>Nc1ccccn1</smiles>

1<smiles>Nc1ccccn1</smiles>

2<smiles>Nc1cccc[nH+]1</smiles>

3<smiles>[N]=c1cccc[nH]1</smiles><smiles>[NH3+]c1ccccn1</smiles>

5
Figure 1. 2-Aminopyridine representations and relation to reactivity

On the other hand, structure 2 forms the 2-aminopiridine cation, 6 , which when is activated by heat, gives structures 7 and 8, "Fig. 2".<smiles></smiles><smiles>[NH2+]=c1cccc[nH]1</smiles>

7<smiles></smiles>

8
Figure 2. High energy resonance structures of 2-aminopyridinium cation

In the excited structure 7 there is a 1,3-dipole arising from the amino group, whereas in semiquinone structure 8 there is a 1, 5-dipole. In both structures, 7 and 8 , there is another 1 , 3-dipole involving the two positive charged nitrogen atoms. This electric repulsion can be eliminated by deprotonation, forming the intermediates 9 and 10, "Fig. 3".<smiles></smiles>

9<smiles>CC1=NCC(=[Tl])C=C1</smiles>

10
Figure 3. Neutral dipole structures as reactive intermediates in 2-aminopyridine nitration

The much higher reactivity of 2-aminopyridine compared with that of pyridine, is in agreement with an electrically neutral substrate, like 9 and 10, instead of the presence of a pyridinium cation in the reaction step, as in pyridine nitration.

Isomers 9 and 10 show 1, 3- and 1, 5-dipoles, respectively, and possess very different reactivities. The nitronium ion 
reacts with the carbanions in 9 and 10 . In the first case there is steric hindrance due to the iminium group, but the major effect is the electric repulsion due to the nitrogen positive-charge (electric hindrance). In structure 10 there is no hindrance and hence 5-nitro-2-aminopyridine is the main product. Besides, the 1,5-dipole in 10 is of higher energy content than the 1 , 3-dipole in 9, and therefore it is more unstable and more reactive than 9 .

Other involved factor is the different carbanion reactivity. In structure 9 the carbanion is closer to the positive charge, thus more stable and less reactive. In intermediate 10 there is an isolated or nude carbanion, then more reactive. All these factors favour 5-nitro-2-aminopyridine formation and explain the high yield of this product.<smiles></smiles>

Quinoline
Isoquinoline

$$
\text { }
$$

\subsection{Short- and long-range electric interactions}

As it was mentioned above, quinoline and isoquinoline nitrations were also studied [8]. When these compounds are nitrated in acidic medium, the acid-base reaction occurs first and a benzopyridinium cation is formed. This favours reaction at the benzene ring due to electric hindrance, i.e., repulsion of the positive nitronium ion by the positive nitrogen atom.

In both compounds, quinoline and isoquinoline, there is mono-nitration: either at C-5 or at C-8. With quinoline, the reaction yields are ca. $50 \%$ in each position, whereas in isoquinoline the yields are completely different: $90 \%$ at C-5 and only $10 \%$ at C-8, [11, 12], "Scheme 4".<smiles></smiles>

5-Nitroquinoline ca. $50 \%$<smiles>O=[N+]([O-])c1cccc2cnccc12</smiles><smiles>O=[N+]([O-])c1cccc2cccnc12</smiles>

8-Nitroquinoline ca. $50 \%$<smiles>O=[N+]([O-])c1cccc2ccncc12</smiles>

8-Nitro-isoquinoline ca. $10 \%$

Scheme 4. Benzopyridines nitration with mixed-acid

Here two interesting questions arise: a) Why the carbocyclic ring reacts at the alpha positions (5 and 8) and not at the beta ones (6 and 7) ?, and b) Why in the quinoline molecule the reaction yields are $1: 1$, whereas in isoquinoline they are 9:1?

We answered these questions [8] as follows: when the previously formed quinolinium cation reacts with a nitronium ion, the $\pi$-complex at the benzene ring must open in a way that the positive charge generated at the vicinal carbon atom is at the farthest position respect to the nearer positive electric charge in any of the quinolinium resonance structures. This way there is the minimum of electric repulsion in the bi-positive cation formed. Thus, the regiochemistry is governed by electric hindrance. For instance, when nitration occurs at C-5 the two positive charges are in a 1, 4-range. If reaction occurred at $\mathrm{C}-6$, the positive charges would be closer, at a 1,3-range. So, the influential quinolinium resonance structure is those with the positive charge at C-4, nearer to the reaction site. The 7-8 double bond reacts at $\mathrm{C}-8$ leaving a positive charge at $\mathrm{C}-7$, farther respect to the nearer positive charge, at C-1 in this case, "Scheme 5".<smiles>c1ccc2[nH+]cccc2c1</smiles><smiles></smiles><smiles>c1ccc2[nH]cc[cH+]c2c1</smiles><smiles>CC1=CC2=CC=CNC2=CC=C1</smiles><smiles>O=[N+]([O-])C1[CH+]C=CC2=C1[CH+]C=C[NH2+]2</smiles><smiles></smiles><smiles></smiles>

Scheme 5. Quinolinium resonance structures and reaction due to electric hindrance

The quinolinium cation presents positive electric charges both at the upper part $(\mathrm{C}-4)$ and in the lower part of the molecule ( $\mathrm{N}-1$ and $\mathrm{C}-2)$. This distribution explains the similar reactivities of both double bonds, 5-6 and 7-8.

On the other hand, the isoquinolinium cation presents only two resonance structures, with a positive charge at C-1 and $\mathrm{N}-2$, respectively. Thus, in this molecule there are two zones: a positive one and the other neutral, "Scheme 6". 


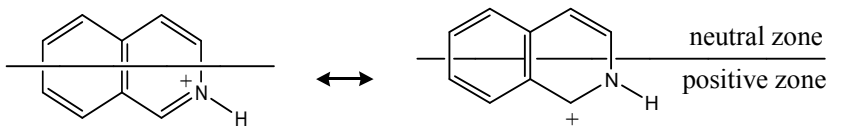

Scheme 6. Reactive zones in isoquinolinium cation that govern the nitration yields

This explains the great reactivity of the 5-6 double bond, which is in the neutral upper-zone, compared to the low reactivity of the 7-8 double bond, located in the positive lower-zone that rejects the nitronium ions. Besides, when the 5-6 double bond reacts, in the resulting bi-positive intermediate the electrical charges are in a 1, 5-range, whereas the 7-8 double bond originates a bi-positive intermediate with nearer charges, i.e., in a 1, 4-range.

As it can be seen, the distribution of the positive electric charge in the resonance structures of the reacting cation is very important because it directs not only the regiochemistry but also the reaction-yields ratio.

The electric hindrance effect is very clear in these reactions, since not being substituents in the substrate, steric hindrance cannot be invoked at all.

\subsection{Autogenic Electromeric Effect}

Linton studied the dipole moments of several amine oxides [13] and found that the dipole moment of pyridine $\mathrm{N}$-oxide is appreciably smaller than the expected theoretical value.

Thus, in addition to the ordinary resonance structures derived from the ground state, "Fig. 4", he proposed the existence of three 'excited structures' as contributors.<smiles>[O-][n+]1ccccc1</smiles><smiles>[O-][n+]1[c-]cccc1</smiles><smiles>O=[N+]1C=C[C+]C=C1</smiles><smiles>[O-][n+]1[c-]cccc1</smiles>

Figure 4. Ground state and ordinary resonance structures of pyridine $\mathrm{N}$-oxide

The high energy structures have an electric negative charge on the ring, instead on the oxygen atom, in order to explain the observed small dipole moment in pyridine N-oxide, "Fig. 5".<smiles>O=[N+]1C=CC=C[C+]1[O-]</smiles><smiles></smiles><smiles>O=[N+]1[C+]C=CC=C1</smiles>

Figure 5. Linton's high energy structures (excited structures) of pyridine $\mathrm{N}$-oxide

There is no doubt about the low dipole value since the microwave spectrum of pyridine $\mathrm{N}$-oxide gave a value even a little smaller [14]. However, only one of the three excited structures has been confirmed, as it will be seen.

Nitration experiments with pyridine N-oxide [15-19] showed that the reaction product is 4-nitropyridine $\mathrm{N}$-oxide, i.e., there is regioselectivity. It is important to note that reaction at $\mathrm{C}-2$ and at $\mathrm{C}-6$ would yield 2-nitropyridine $\mathrm{N}$-oxide, and in a double quantity than that obtained of 4-nitropyridine N-oxide, which is not the case at all. From these experimental results, we discard the excited structures with negative charge at C-2 and at C-6.

Moreover, ${ }^{13} \mathrm{C}$ NMR spectroscopy [20] only indicates higher electronic density at $\mathrm{C}-4$ in pyridine $\mathrm{N}$-oxide. This is in agreement with the results of reactions performed much earlier. However, the only acceptable of Linton's structures presents several problems that we have solved recently [21].

The comparison of the reactivity of pyridine has been made [22]. The N-oxide nitration (at C-4) can be effected much more readily that with pyridine, although the reaction is still more difficult than the nitration of benzene [23-25]. This comparison is interesting because it lets us see that even a structure with a carbanion at $\mathrm{C}-4$, and reacting with a nitronium ion, presents a lower reactivity than benzene. So, we deduce that there must be a low population of molecules having that structure.

Moreover, Linton did not gave an explanation as how the high-energy excited-structures can result. The formation of any of them implies an electronic shift contrary to the mesomeric effect of the iminium ion present in the ground state of pyridine N-oxide. In order to form the proposed ylides, the electron-donor effect of the oxygen atom must surpass the opposite mesomeric effect. Thus, a promoter is required. We propose the existence of polarization by intermolecular induction, i.e., participation of an external ion (electromeric effect). In the absence of other reactant, we deduce the participation of the resonance structure with a positive charge at C-4. This electromer [26, 27], with a 1,5-dipole is the most unstable of the ordinary resonance structures, and therefore the most reactive, and can attract electrons from a molecule in the ground state, as is shown in "Scheme 7".

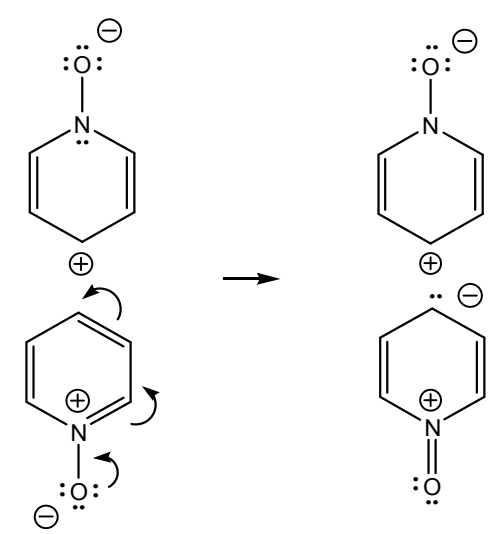

Scheme 7. Interaction of the ground state and an ordinary resonance structure in pyridine $N$-oxide to induce abnormal polarization and formation of an electrostatic dimer

This intermolecular induction can be considered an especial case of the electromeric effect, since the external ion does not come from an added reagent. We must take into account that the dipole moment of pyridine $\mathrm{N}$-oxide was determined in 
benzene, a non-polar molecule.

Thus, this novel interaction can be termed Autogenic Electromeric Effect.

\section{References}

[1] W. M. Cumming, I. V. Hopper, and T. S. Wheeler, Systematic Organic Chemistry, 4th. ed., London: Constable, 1950, p. 280.

[2] K. Bahadur, and W. D. Patwardhan, "Preparation of o-nitroacetanilide", Curr. Sci., vol. 37(17), p.492, 1968.

[3] F. Sánchez-Viesca, R. Gómez, and M. Berros, "Electric hindrance and precursor complexes in the regiochemistry of some nitrations", J. Chem. Ed., vol. 88(7), pp. 944-946, 2011. DOI: dx.doi.org/10.1021/ed900030s

[4] M. Haouas, S. Bernasconi, A. Kogelbauer, and R. Prins, "An NMR study of the nitration of toluene over zeolites by nitric acid/acetic anhydride", Phys. Chem. Chem. Phys., vol. 3, pp.5067-5075, 2001.

[5] Bond Polarization-Temporary Effects-Electromeric Effect (Online, access with the title). Tutors on Net, 2013.

[6] J. W. Baker, Electronic Theories of Organic Chemistry, Oxford: Clarendon Press, 1958, pp. 56-58.

[7] F. Sánchez-Viesca, and R. Gómez, "Electric hindrance and dipole moments in 2-aminopyridine nitration", Am. J. Chem., vol. 5(1), pp. 19-22, 2015. DOI: 10.5923/j.chemistry.20150501.03

[8] F. Sánchez-Viesca, and M. Berros, "Espectroscopía y teoría de la regioquímica en la nitración de las benzopiridinas", TIP Rev. Esp. Cienc. Quim. Biol., vol. 9(1), pp. 19-29, 2006; oai:unam.redalyc.org:43290103

[9] E. Tchitchibabin, "Nitration of 2-aminopyridine", J. Russ. Phys. Chem. Soc., vol. 46(11), pp.1236-1244, 1914; in J. Chem. Soc., London, vol. 108-I, pp.591-592, 1915.

[10] E. Tchitchibabine, "Nitration de l' $\alpha$-aminopyridine", J. Soc. Phys. Chim. Russ., vol. 46(11), pp.1236-1244, 1914; in Bull. Soc. Chim. Fr., series 4, vol. 18, pp. 623-625, 1915.

[11] B. C. Uff, Pyridines and their benzo derivatives: reactivity of substituents, in A. R. Katritzky and C. W. Rees, eds., Comprehensive Heterocyclic Chemistry, Oxford: Pergamon, 1984, vol. 2, part 2A, p. 317.

[12] T. L. Gilchrist, Heterocyclic Chemistry, 3rd. ed., Essex: Longman, 1997, p. 166.

[13] E. P. Linton, "The dipole moments of amine oxides", J. Am. Chem. Soc., vol. 62(8), pp. 1945-1948, 1940.
[14] R. D. Brown, F. R. Burden, and W. Garland, "Microwave spectrum and dipole moment of pyridine N-oxide", Chem. Phys. Lett., vol. 7(4), pp. 461-462, 1970.

[15] E. Ochiai, "A new classification of tertiary amine oxides", Proc Imp. Acad. Tokyo, vol. 19, pp. 307-311, 1943; Chem. Abstr., vol. 41 , col. 5880 d, 1947.

[16] E. Ochiai, E. Hayashi, and M. Katada, "Polarization of aromatic heterocyclic compounds. LVII. Nitration of pyridine 1-oxide", Yakugaku Zasshi (J. Pharm. Soc. Japan), vol. 67, pp. 79-81, 1947; Chem. Abstr., vol. 45, col. 9538a, 1951.

[17] E. Ochiai, and E. Hayashi, "Nitration of pyridine 1-oxide", Yakugaku Zasshi (J. Pharm. Soc. Japan), vol. 67, p. 157, 1947; Chem. Abstr., vol. 45, col. 9541c, 1951.

[18] H. J. den Hertog, and W. P. Combé, "Reactivity of 4-nitropyridine N-oxide: Preparation of 4-substituted derivatives of pyridine N-oxide and pyridine", Rec. Trav. Chim., vol. 70(7), pp. 581-590, 1951.

[19] Notice of Preparation (NOP) 1004 Nitration of pyridine N-oxide to 4-nitropyridine N-oxide; Bremen University, 2006, http://kriemhild.uft.uni-bremen.de/nop/en /instructions/pdf/1004_en.pdf

[20] F. A. L. Anet, and I. Yavari, "Carbon-13 nuclear magnetic resonance study of pyridine N-oxide", J. Org. Chem., vol. 41(22), pp. 3589-3591, 1976.

[21] F. Sánchez-Viesca, and R. Gómez, "Polarization by intermolecular induction in pyridine N-oxide and its nitration", Am. J. Chem., vol. 3(5), pp. 136-139, 2013. DOI: 10.5923/j.chemistry.20130305.03

[22] R. A. Barnes, "A comparison of the structure and reactivity of pyridine and pyridine 1-oxide", J. Am. Chem. Soc., vol. 81(8), pp. 1935-1938, 1959.

[23] A. A. Morton, The Chemistry of Heterocyclic Compounds, New York: McGraw-Hill, 1946, p. 211.

[24] L. Gattermann, Laboratory Methods of Organic Chemistry, London: Macmillan, 1957, pp. 161-162.

[25] W. M. Cumming, I. V. Hopper, and T. S. Wheeler, Systematic Organic Chemistry, 4th. ed., London: Constable, 1950, pp. 276-277.

[26] J. H. White, A Reference Book of Chemistry, London: University of London Press, 1960, p. 47.

[27] Collins English Dictionary Complete and Unabridged, "Electromerism", New York: Harper Collins Publishers, 2003. 